피사계심도 확장을 위한 대역통과 필터 기반 초점 정량화 기법

차 수 람a), 김 정 태 ${ }^{a{ }^{\ddagger}}$

\title{
Bandpass Filter Based Focus Measure for Extended Depth of Field
}

\author{
Suram $\mathrm{Cha}^{\mathrm{a})}$ and Jeongtae $\mathrm{Kim}^{\mathrm{a})^{\ddagger}}$ \\ 요 약
}

본 논문에서는, 피사계심도가 낮은 카메라로 획득한 영상에서 초점이 맞는 부분과 그렇지 않은 부분을 나누는 새로운 초점 정량화 를 설계하고 초점 정량화에 기반한 decision map을 이용하여 획득한 영상과 위너필터링으로 복원한 영상의 정합을 통해 영상의 피사 계심도를 확장하였다. 기존의 초점 정량화 방법은 고주파 성분의 크기에 따라서 초점 정량화를 수행하므로 초점이 맞지 않은 부분에 고주파 성분이 있는 경우 성능이 저하된다는 단점이 있다. 본 논문에서는 이를 극복하기 위하여 효과적인 대역필터를 설계하였으며 제 안하는 방법이 기존에 방법에 비해서 성능이 우수함을 시뮬레이션 및 실험을 통해 입증하였다.

\begin{abstract}
In this paper, we propose a novel focus measure that determines in-focus and out-of-focus region in an image. In addition, we achieved extended depth of field by blending the acquired image and Wiener filtered image using a decision map based on the designed focus measure. Since conventional focus measures are based on the amount of high frequency components in an acquired image, the measures may not be accurate if there exist high frequency components in out-of-focused region. To overcome the problem, we designed the novel focus measure based on effective band pass filtering. In simulations and experiments, the proposed method showed better performance than existing methods.
\end{abstract}

Keyword : EDoF, DoF, Wiener filter, focus measure, decision map

\section{I. 서 론}

피사계심도 (DoF: Depth of Field)란 카메라 렌즈로 피사 체를 잡을 때 카메라 렌즈에 맺힌 피사체의 상이 뚜렷하게 보일 수 있는 가장 가까운 거리와 가장 먼 거리 사이의 범위

\footnotetext{
a) 이화여자대학교 전자공학과

Dept. of Electronics Engineering, Ewha Womans University

\# 교신저자 : 김정태 (jtkim@ewha.ac.kr)

※ 이 논문은 하이닉스 반도체와 2008년 정부(교육과학기술부)의 재원으 로 한국학술진흥재단의 지원을 받아 수행된 연구임 (KRF-2008-331D00419).

· 접수일(2011년8월17일),수정일(2011년9월19일),게재확정일(2011년9월19일)
}

를 지칭한다 ${ }^{[1]}$. 일반적으로 렌즈의 조리개 값이 작을수록, 피사체와의 거리가 멀수록, 초점거리가 짧을수록 피사계심 도가 크다. 피사계심도가 낮은 렌즈로 영상을 획득하게 되 면, 한 영상 내에 초점이 맞은 영역과 그렇지 않은 영역이 모두 존재하므로 획득한 영상은 공간에 따라 변화하는 (spatial varying) PSF (Point Spread Function)에 의해서 블 러된 것으로 모델링 된다. 따라서 영상에서 초점이 맞지 않 아 부분적으로 블러된 영역을 초점이 맞게 만들어야 할 필 요를 가지며 이를 피사계심도 확장 $(\mathrm{EDoF}:$ Extended Depth of Field)이라 부른다.

피사계심도를 확장하기 위하여 기존에 제안된 방법은 하 
드웨어 접근법과 소프트웨어 접근법으로 나눌 수 있다. 먼 저, 하드웨어 접근법 중 웨이브 프론트 코딩 시스템 (wavefront coding system)은 카메라 렌즈 가까이에 비대칭 굴절 마스크를 삽입하는 방법으로 마스크에 의해 특정한 $\mathrm{PSF}$ 로 영상을 인코딩 하는 방법이다 ${ }^{[2]}$. 인코딩된 영상은 공간에 독립적인 PSF를 가지기 때문에 디코더 시스템에서는 공간 불변한 영상 복원 방법을 사용할 수 있다 ${ }^{[2-4]}$. 하지만 웨이 브 프론트 코딩 시스템의 방법은 공간 불변한 PSF를 만들 기 위한 굴절 마스크를 제작할 때 물리적인 어려움이 있고 디코더의 영상 복원 과정에서 SNR (Signal to Noise Ratio) 이 줄어들어 영상 열화를 일으킬 수 있을 뿐만 아니라, 렌즈 를 제작함에 있어서 비용의 문제가 크다는 단점을 가진다. 또 다른 방법인 sharpness transport 기술은 파장에 따른 굴 절률의 차이에 의해 생기는 색수차를 이용한 방법이다 ${ }^{[5]}$. 즉, R(Red), $\mathrm{G}(\mathrm{Green}), \mathrm{B}(\mathrm{Blue})$ 채널은 각각 파장이 다르기 때문에 영상 평면에서 다르게 상이 맺혀져 렌즈와 가까운 곳은 $\mathrm{B}$ 채널이 $\mathrm{R}$ 과 $\mathrm{G}$ 에 비해 더 뚜렷하고, 먼 곳은 $\mathrm{R}$ 이 중간 거리는 $\mathrm{G}$ 가 더 뚜렷하게 맺히게 되는데, 이런 색수차 를 광학 시스템에 적용하여 렌즈를 디자인 하는 방법이다. 이 방법 또한 웨이브 프론트 코딩 방법과 같이 렌즈를 만드 는데 있어서 물리적인 한계점 및 비용 문제에 부딪친다. 소 프트웨어 접근법은 한 장의 영상 또는 여러 장의 영상으로 피사계심도를 확장하는 방법으로 나눌 수 있다. 먼저, 여러 장의 영상을 이용하는 방법으로는 대표적으로 depth sensing을 이용하는 방법이 있다 ${ }^{[6]}$. 이 방법은 각 영상 마다 초 점 정량화 (focus measure)를 이용하여 초점이 맞은 부분 들을 찾고 그 영상들을 정합하는 방법이다. 초점이 맞은 부분을 정의하는 방법에 따라 크게 point 기반 영상 정합 기법, neighborhood 기반 영상 정합 기법, 그리고 multi-resolution 기반 영상 정합기법으로 구분할 수 있다 ${ }^{[7-9]}$. Point 기반 영상 정합 기법은 모든 영상 내에 똑같은 좌표 의 밝기 값을 비교하여 그 값들 중 가장 밝은 값 혹은 가장 어두운 값을 선택하여 focusing 된 하나의 영상을 만드는 방법이고 ${ }^{[7]}$, neighborhood 기반 영상 정합 방법은 그 픽셀 의 이웃 화소들과의 분포를 파악하여 초점이 맞은 영상을 선택하는 방법이다 ${ }^{[8]}$. 마지막으로 multi-resolution 기반 영 상정합 방법은 초점이 맞춰진 부분의 경우 일반적으로 경
계들이 섬세하게 표현되는 반면 초점이 맞지 않는 부분은 블러 된다는 사실을 이용하여 피사계심도가 낮은 획득 영 상을 퓨리에 변환 한 후 고주파수 양으로 초점이 맞은 영 역을 찾는 방법이다미. 하지만 퓨리에 변환을 하면 주파수 정보는 알 수 있지만 공간 정보는 잃어버리게 되는 한계점 을 가진다. 이를 보완하여 영상 내에 윈도우를 적용하는 STFT (Short Time Fourier Transform) 의 경우도 윈도우의 크기에 따라 성능이 좌우되는 단점을 가진다. 위의 방법과 유사하게 거리에 따라 초점이 맞은 여러 장의 영상을 이용 하여 정합하는 multi-focus image fusion 방식도 제안되었 다 ${ }^{[10]}$. 하지만 초점이 맞은 영역만 분할 (segmentation) 하 여 정합하는 방법은 분할을 완벽하게 수행할 수 없고, 초 점이 각각 다르게 맞은 여러 장의 영상을 얻어야 한다는 단점을 가진다.

한 장의 영상으로 피사계심도를 확장하는 방법은 초점 정량화를 이용하여 획득한 영상에서 초점이 맞은 부분과 그렇지 않은 부분을 나눈 decision map을 구한다. 그 후, 이를 이용하여 획득한 영상과 초점이 맞지 않은 부분의 $\mathrm{PSF}$ 에 맞추어 필터링한 영상과의 정합 과정을 통해 복원하 게 된다. 초점 정량화는 한 장의 영상에서 초점이 맞은 여부 를 나눌 때에도 필요하지만 여러 영상을 이용하여 초점이 맞은 부분을 나누어 정합하는 multi-focus image fusion 방 식 등에서도 필요한 방법이다. 기존에 제안된 초점 정량화 방법은 획득한 영상의 고주파수의 양이나, 엔트로피 (entropy), 그리고 픽셀 값 (intensity)의 분산 (variance) 등 을 이용하여 초점의 정도를 나누었담1-16]. 즉, 한 영상 내에 서 고주파수의 양이 많은 영역일수록, 주파수 도메인에서 엔트로피 값이 작을수록, 그리고 주변 영역에서의 분산이 클수록 다른 영역에 비해 초점이 맞은 영역이라 판단하는 방법이다. 하지만 위의 초점 정량화 기준법은 단순하게 획 득한 영상에서 고주파수 양이 많을수록, 더 초점이 맞은 영 역이라 판단하기 때문에 초점이 맞지 않는 부분에 고주파 성분의 문자나 잡음이 끼여 있는 경우, 판단의 오차로 인해 복원 과정에 영향을 주어 피사계심도를 확장하는데 어려움 을 가진다. 잡음의 영향을 고려하여 초점 정량화를 모델링 하는 접근법으로는 DWT (Discrete Wavelet Transform)를 이용하는 방법이 있다 ${ }^{[17]}$. 이는 DWT를 통해 얻은 영상 중, 
coarse한 영상을 제외하고 fine한 레벨의 영상 중에서 잡음 의 표준편차와 관련된 임계값에 의해 hard thresholding하 여 잡음의 영향이 DWT 계수의 에너지 보다 큰 레벨의 영 상을 무시하는 방법을 취하고 있다. 이 방법은 잡음의 영향 을 고려하였지만 thresholding을 하기 위하여 잡음의 표준 편차에 대한 정보가 기본적으로 주어져야 초점이 맞은 부 분과 그렇지 않은 부분을 나눌 수 있는 한계점을 지닌다. 따라서 본 논문은 기존에 제안된 초점 정량화 방법의 한계 점을 개선하는 대역 필터를 기반으로 한 초점 정량화 방법을 제안한다. 또한 초점 정량화를 이용하여 초점이 맞지 않은 부분에 위너 필터 (Wiener filter)를 적용하고 획득한 영상과 위너 필터링 된 영상과의 정합 (blending)과정을 통해 피사 계심도를 확장함을 실험을 통해 입증한다. 본 논문은 기존에 제안된 초점 정량화 방법에 대한 설명, 제안하는 초점 정량 화 방법, 실험 결과 및 분석 등으로 구성되어 있다.

\section{II. 기존 초점 정량화 연구}

기존에 제안된 초점 정량화 방법중 널리 사용되는 방법 으로는 전통적인 $\mathrm{SML}$ 방법과 지역분산을 적용한 방법, 엔 트로피 그리고 DCT를 사용하는 방법 등이 있다 ${ }^{[11-16]}$. 위에 서 언급한 방법들은 모두 잡음의 영향을 고려하지 않고 단 순히 고주파수 성분의 양에 따라 초점 정도를 판단방법이 므로 모두 유사한 접근법이라 할 수 있다. 본 본문에서는 최근에 피사계심도를 확장하기 위하여 제안된 [13]과 [14] 의 초점 정량화 연구에 대하여 다음에 설명하고 이 방법들 과 본 연구에서 제안하는 방법의 성능을 비교한다.

\section{Local Sum-Modified Laplacian (SML) Criterion}

일반적으로 라플라시안은 고주파 성분을 추정하는 연산 자로 알려져 있다. 하지만 영상의 특정 위치에서 수평방향 과 수직방향으로 이차 미분한 값이 크기는 같고 부호만 다 를 때, 이차 미분 값이 서로 상쇄되어 고주파 성분의 크기를 잘못 추정하게 된다. 따라서 Nayer는 아래의 식 (1)과 같이 라플라시안 미분 연산자를 변형하여 SML (Sum Modified
Laplacian)을 제안하였다 ${ }^{[11-13]}$.

$$
\nabla^{2} f(x, y)=\left|\frac{\partial^{2} f(x, y)}{\partial x^{2}}\right|+\left|\frac{\partial^{2} f(x, y)}{\partial y^{2}}\right|,
$$

여기서 $f$ 를 획득한 영상이라 할 때, $\nabla^{2} f(x, y)$ 는 $f$ 를 $x$ 방향과 $y$ 방향으로 각각 두 번 미분을 한 후 절대값을 쓰 워 더한 것을 의미한다. 따라서 SML 연산자를 이용하여 $(x, y)$ 위치에서 초점 정량화 $m(x, y)$ 을 식 (2)와 같이 구 할 수 있다.

$$
m(x, y)=\sum_{x^{\prime}, y^{\prime} \in S(x, y)} \nabla^{2} f\left(x^{\prime}, y^{\prime} ; x, y\right),
$$

여기서 $\nabla f^{2}\left(x^{\prime}, y^{\prime}\right)$ 는 특정 위치 $\left(x^{\prime}, y^{\prime}\right)$ 에서의 $\mathrm{SML}$ 값을 의미하고, 초점 정량화 $m(x, y)$ 값은 $(x, y)$ 를 중심의 $S(x, y)$ 블록 내부 픽셀의 $\mathrm{SML}$ 값을 합한 값을 의미한다. $\mathrm{SML}$ 을 이용한 초점 정량화 방법은 초점이 맞은 영역일수 록 초점이 맞지 않는 영역에 비해 고주파수 성분을 많이 가지고 있을 것이라고 가정하는 방법이다. 하지만 위의 방 법은 단순 고주파 통과 (HPF: High Pass Filter)의 역할을 하기 때문에 초점이 맞지 않은 영역에 잡음이 섞여 있거나 텍스트 영상과 같이 고주파 성분이 많이 존재할 경우 초점 정량화의 성능이 떨어질 수 있다는 문제점을 가지고 있다.

\section{Local Variance Criterion}

지역적 분산 (local variance)을 이용하여 만든 초점 정량 화 방법은 초점이 맞은 영역이 그렇지 않은 영역에 비해 픽셀 값의 변화가 더 크다는 가정 하에 이를 이용하여 초점 정량화를 식 (3)과 같이 설계 한다 ${ }^{[14]}$.

$$
m(x, y)=1-\frac{1}{1+\sigma v(x, y)},
$$

여기서 $\sigma$ 는 튜닝 파라미터로 이 값이 커질수록 가중치의 기울기가 더 커지는 경향을 가진다. $v(x, y)$ 는 특정 픽셀 $(x, y)$ 을 중심으로 $M \times N$ 윈도우 $S$ 내부의 화소 값의 분 산을 의미하고 이는 식 (4), (5)와 같이 정의된다. 


$$
\begin{gathered}
v(x, y)=\frac{1}{M N} \sum_{x^{\prime}, y^{\prime} \in S}\left\{f\left(x^{\prime}, y^{\prime} ; x, y\right)-f_{m}(x, y)\right\}^{2}, \\
f_{m}(x, y)=\frac{1}{M N} \sum_{x^{\prime}, y^{\prime} \in S} f\left(x^{\prime}, y^{\prime} ; x, y\right),
\end{gathered}
$$

여기서 $f_{m}(x, y)$ 는 특정 픽셀 $(x, y)$ 을 중심으로 한 블 록의 평균을 말한다. 식 (4), (5)와 같이 정의되는 지역적 분산을 이용한 방법도 SML 방법과 마찬가지로 획득한 영 상에 단순히 고주파 대역통과를 하는 역할을 하기 때문에 영상의 특징에 따라 성능이 좌우되는 단점을 가진다.

\section{III. 제안하는 방법}

피사계심도를 확장하기 위하여 제안하는 방법은 아래의 블록 다이어그램과 같이 먼저 획득 영상의 R, G, B 채널을

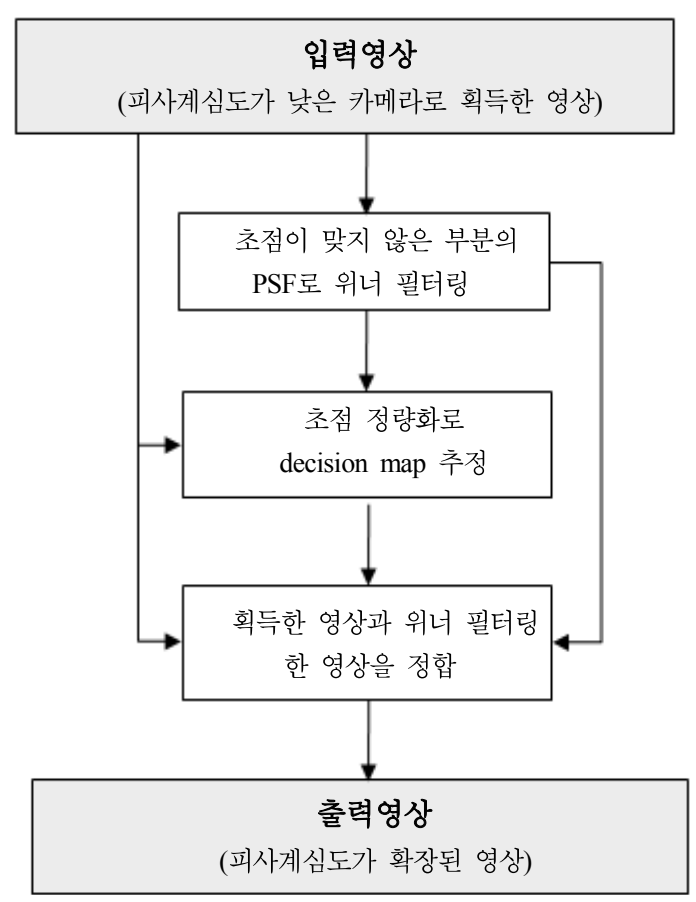

그림 1. 제안하는 방법의 블록 다이어그램

Fig. 1. Block diagram of proposed method
위너 필터링 한 후, 획득한 영상과 위너 필터링 된 영상을 이용한 초점 정량화 방법으로 초점이 맞은 부분과 그렇지 않은 부분을 나누는 decision map을 구한다. 이후 구한 decision map을 이용하여 획득한 영상과 전체적으로 위너 필 터링 한 영상과 정합함으로써 피사계심도가 확장된 영상을 얻는다.

\section{1. 초점 정량화 (Focus measure)}

특정 위치에서 그 픽셀이 초점이 맞았는지 아닌지를 판 단하기 위하여, 기존의 초점 정량화 방법은 획득한 영상의 특정 위치에 대한 블록을 단순히 고주파 대역통과 한 값을 합한 것으로 decision map을 추정한다. 그러므로 초점이 맞 지 않은 영역의 피사체가 고주파수 성분을 가지고 있거나 잡음이 추가 되었을 경우에는 초점이 맞지 않은 영역도 초 점이 맞는 부분이라 추정하는 한계점을 가진다. 본 논문에 서는, 이를 보완하기 위하여 획득한 영상과 그 영상을 전체 적으로 위너 필터링 한 영상과의 관계를 고려하여 가중치 를 주는 초점 정량화 방법을 제안한다.

즉, 기존의 방법인 고주파 대역으로 갈수록 가중치가 커 지는 고주파 대역통과의 한계점을 보완하여 잡음의 영향을 줄일 수 있도록 본 연구에서는 주파수 대역에서 가중치를 식 (6)과 같이 설계한다.

$$
g(x, y)=\sum_{u, v} w(u, v)|F(u, v ; x, y)|^{2},
$$

여기서 영상의 특정 위치 $(x, y)$ 를 중심으로 한 블록 $S$ 의 퓨리에 변환을 $F(u, v ; x, y)$ 라 하면 $g(x, y)$ 는 영상의 특정 위치를 중심으로 $S$ 의 크기만큼 둘러싸고 있는 블록을 퓨리 에 변환 후, 퓨리에 변환의 크기 (magnitude)의 제곱에 대하 여 식 (7)의 $w(u, v)$ 만큼 가중치를 주어 합한 것을 의미한 다.

$$
w(u, v)=e^{-\frac{u^{2}+v^{2}}{2 \sigma^{2}}}\left(1-e^{-\frac{u^{2}+v^{2}}{2 \sigma^{2}}}\right),
$$

여기서 $w(u, v)$ 는 주파수 대역에 대한 가중치이고, $\sigma$ 값 
은 주파수 대역에 대하여 가중치의 정도를 결정하는 파라 미터로 아래 그림 2와 같이 $\sigma$ 값이 작아질수록 고주파 대 역의 가중치를 줄이는 역할을 한다. 따라서 적절한 $\sigma$ 의 값 에 의해 고주파의 가중치를 줄임에 따라 초점이 맞은 영역 과 아닌 영역을 판단 할 때 잡음의 영향에 대한 조절이 가능 하다.

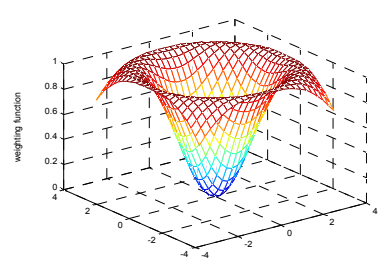

(a)

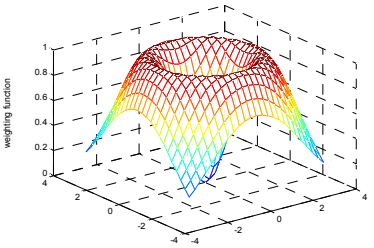

(b)
그림 2. $2 \mathrm{D}$ 기중치 함수, (a) 블록 사이즈 $25 \times 25, \sigma=10$ (b) 블록 사이즈 $25 \times 25, \sigma=7$

Fig. 2. 2-dimensional weighting function, (a) Block size $25 \times 25, \sigma=10$ (b) Block size $25 \times 25, \sigma=7$

또한 식 (6)의 가중치 외에도 위너 필터의 특성을 이용하 면 초점이 맞은 영역과 맞지 않은 영역을 나누는 초점 정량 화의 성능을 개선할 수 있다. 위너 필터는 잡음 대비 신호의 비율 (NSR: Noise to Signal Ratio)의 값에 따라 고주파 대 역의 잡음의 영향을 줄이면서 적절한 대역을 통과시키는 필터이기 때문에 비교적 에지가 선명할수록 신호의 크기를 더 증가시키기는 역할을 한다. 초점이 맞는 부분은 그렇지 않은 부분에 비해 에지가 선명하므로 스펙트럼 도메인에서 위너필터링 전 후의 영상에 대한 고주파수 성분 크기의 증 가량이 더 크다. 따라서 본 논문에서는 제안하는 가중치 함 수를 획득한 영상과 위너 필터링 한 영상에 대하여 적용하 여 식 (8)과 같이 초점이 맞은 부분과 그렇지 않은 부분을 구분하는 초점 정량화 $m_{p}(x, y)$ 를 제안한다.

$$
m_{p}(x, y)=g_{R}(x, y)-g_{f}(x, y),
$$

여기서 $g_{f}(x, y)$ 는 획득한 영상 $f$ 에 대하여, $g_{R}(x, y)$ 는 획득한 영상을 위너필터링 한 영상에 대하여 식 (6)을 적용 한 것을 의미하고, $(x, y)$ 의 위치에서 제안하는 초점 정량
화 $m_{p}(x, y)$ 는 $g_{R}(x, y)$ 와 $g_{f}(x, y)$ 의 차이로 설계한다. 제안 하는 초점 정량화 방법의 가중치에 대한 식 (8)을 주파수 대역 스펙트럼에서 분석하면 식 (9)와 같이 정리할 수 있다.

$$
\begin{aligned}
m_{p}(x, y) & =g_{R}(x, y)-g_{f}(x, y) \\
= & \sum_{u, v} w(u, v)|F(u, v ; x, y)|^{2}|R(u, v)|^{2}- \\
& \sum_{u, v} w(u, v)|F(u, v ; x, y)|^{2} \\
= & \sum_{u, v}|F(u, v ; x, y)|^{2} w(u, v)\left\{|R(u, v)|^{2}-1\right. \\
& =\sum_{u, v}|F(u, v ; x, y)|^{2} B_{w}(u, v),
\end{aligned}
$$

여기서 획득한 영상의 특정 위치 $(x, y)$ 를 중심으로 한 블록을 퓨리에 변환 한 것은 $F(u, v ; x, y)$ 이고 $w(u, v)$ 는 가 중치 함수를, $|R(u, v)|^{2}$ 는 위너 필터의 주파수 도메인에 서의 크기 응답 (magnitude response) 의 제곱을 의미한다. 식 (9)에서 가중치 함수와 위너 필터의 주파수 크기 응답 은 각각 그림 3 의 (a), (b)와 같고 (c)는 식 (9)의 $w(u, v)\left\{|R(u, v)|^{2}-1\right\}$ 부분을 정리해서 얻은 대역통과 필터 (BPF: Band Pass Filter) 형태를 가지는 $B_{w}(u, v)$ 의 $1 \mathrm{D}$ 그래프를 나타내고 (d)는 주파수 도메인에서 SML 방법 과 유사한 특성을 가지는 가중치 함수를 의미한다. SML 방 법은 절대값에 의해 비선형적인 연산자의 특성을 갖기 때 문에 단순 주파수 응답을 그래프로 나타내기에는 어려움을 갖는다. 그러므로 그림 3의 (d)는 SML의 절대값 연산자 대 신 2차 미분을 제곱한 제곱 라플라시안 연산자에 대한 주파 수 도메인에서의 가중치 함수를 나타낸 것이다.

그림 3의 (c)와 (d)를 비교해 보면, (d)는 획득한 영상의 주파수 스펙트럼의 크기인 $|F(u, v)|^{2}$ 를 단순 고주파 대역 통과하기 때문에 초점이 맞지 않는 부분에 잡음이 있는 경 우에도 가중치를 줄 뿐만 아니라 저주파 대역의 신호인 경 우에도 어느 정도의 가중치를 주기 때문에 초점 정량화의 역할을 잘 하지 못할 수 있다는 것을 알 수 있다. 이에 비해 제안하는 초점 정량화 방법은 $|F(u, v)|^{2}$ 의 신호에 대하여 고주파 대역에 있는 잡음의 영향을 줄이면서 저주파 대역 에서는 가중치를 주지 않기 때문에 기존의 방법에 비해 초 점이 맞은 부분과 그렇지 않은 부분을 잘 나눌 수 있다. 


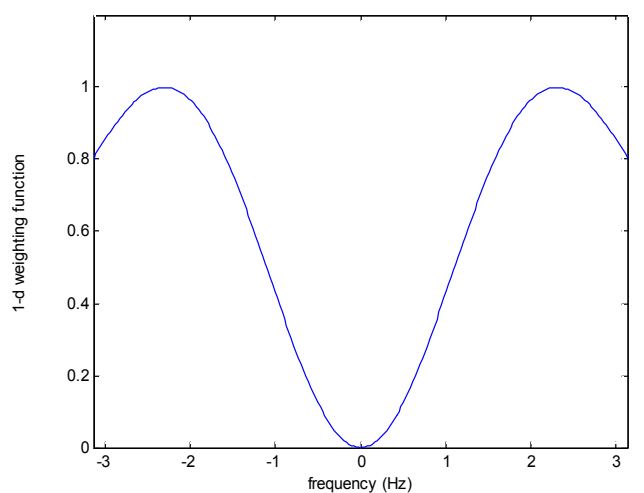

(a)

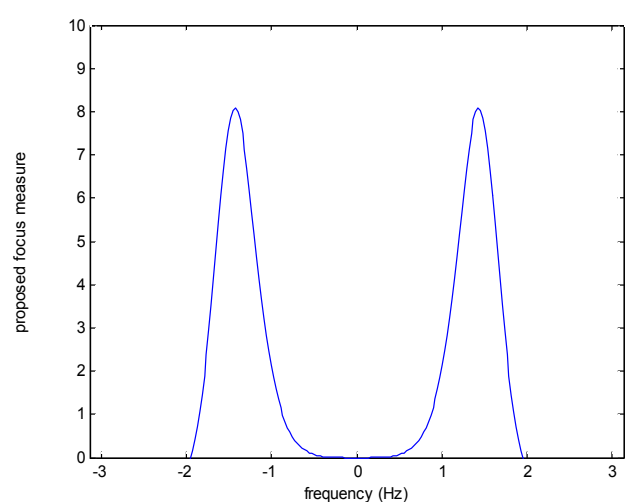

(c)

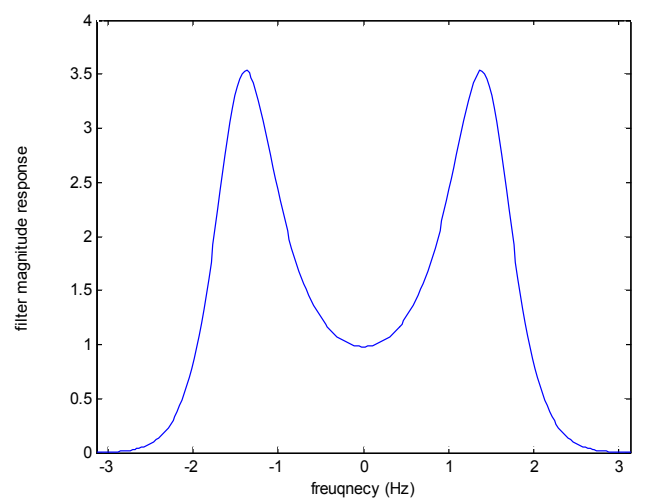

(b)

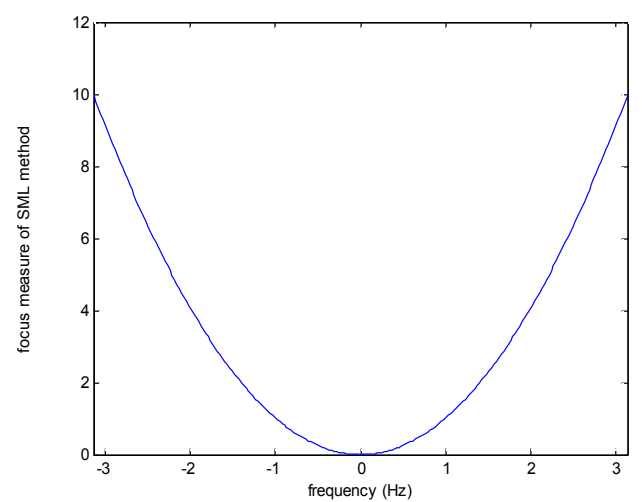

(d)

그림 3. 1D 주파수 응답, (a) 가중치 함수 (b) 위너 필터의 주파수 응답 그래프, (c) 제안하는 방법의 초점 정량화 방법 (d) SML과 유사한 특성을 가지는 제곱 라플라시안

Fig. 3. 1D frequency response, (a) Weighting function (b) Magnitude response of Wiener filter, (c) Proposed focus measure (d) Focus measure of squared Laplacian method

\section{2. 위너 필터 (Wiener filter)}

위너 필터는 선형 최소 오차 필터로써, 원 영상과 잡음의 파워 스펙트럼 그리고 PSF가 알려져 있을 경우 효과적으로 영상을 복원할 수 있으며 식 (10)과 같이 정의된다.

$$
R^{c}(u, v)=\frac{H^{*}(u, v)}{\left|H^{c}(u, v)\right|^{2}+N S R},
$$

여기서 $c$ 는 R, G, B 채널을 의미하고 NSR은 잡음 대비 신호의 비율을, $H(u, v)$ 는 PSF의 퓨리에 변환을, $H^{*}(u, v)$
은 $H(u, v)$ 의 복소 공액이다. 따라서 식 (9)에 의해 $c$ 채널 에 대한 위너 필터 $R^{c}$ 를 구할 수 있다. 위너 필터는 공간 불변한 (spatial invariant) PSF에 대한 복원 기법이므로, 초 점이 맞은 영역과 맞지 않은 영역이 모두 존재 하여 공간에 따라 변하는 (spatial varying) PSF 에 의해 열화된 영상인 경우, 초점이 맞지 않은 영역의 $\mathrm{PSF}$ 로 위너 필터를 적용해 보면 초점이 맞은 부분에 artifact가 발생한다. 이러한 문제 를 개선하기 위하여 식 (9)와 같이 설계된 초점 정량화를 사용하여 획득한 영상과 위너 필터링을 수행한 영상을 정 합한다. 


\section{3. 정합 (Blending)}

피사계심도가 낮은 카메라로 획득한 영상과, 획득 영상 의 초점이 맞지 않은 영역에 맞춘 $\mathrm{PSF}$ 로 위너 필터링을 한 영상을 초점 정량화로 구한 decision map으로 식 (11)과 같 이 정합하여 피사계심도가 확장된 영상을 얻는다.

$$
\begin{gathered}
O(x, y)=\widehat{m}_{p}(x, y) \times f(x, y)+\left(1-\widehat{m}_{p}(x, y)\right) f_{R}(x, y) \\
\widehat{m_{p}}(x, y)=\frac{\min (\max (0, m(x, y)), T)}{T} \\
T=\alpha \max (m(x, y)),
\end{gathered}
$$

여기서 $f$ 는 획득한 영상, $f_{R}$ 은 위너필터링을 적용한 영 상을 말하고 $\widehat{m_{p}}$ 는 decision map $m_{p}$ 를 식 (12)로 정규화 한 것을 의미한다. 정규화는 획득한 영상과 위너필터링 한 영상을 정합하기 위하여 III-1에서 구한 decision map이 $[0,1]$ 사이의 값을 가져야 하기 때문에 필요하며, 본 논문에 서는 $\alpha$ 를 0.8 로 했을 때의 임계 값 $T$ 로 정규화 하였다.

\section{IV. 실험 결과 및 분석}

Nikon D80의 IF 28 75mm 1:2.8 렌즈로 배경에 초점을

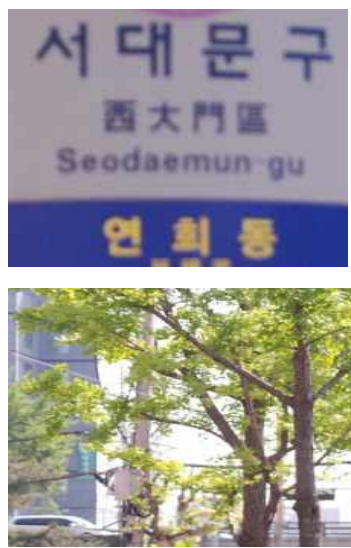

(a)
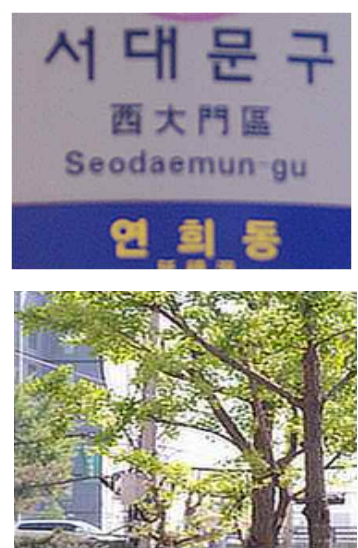

(b)
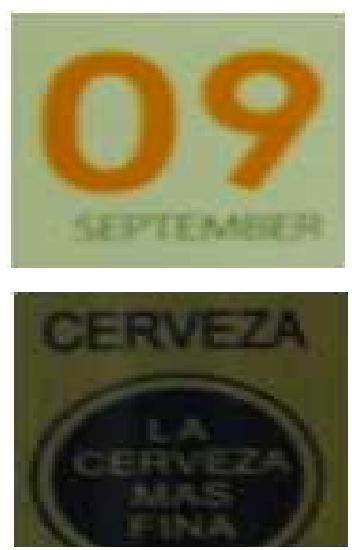

(c)
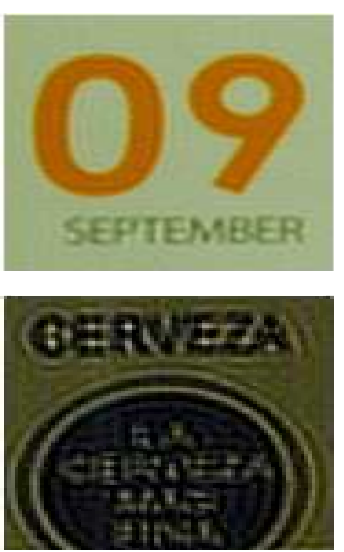

(d)

그림 5. (a),(c) 전경과 배경을 확대한 영상 (b),(d) PSF를 전경에 맞추어 위너 필터링 한 것을 확대한 영상

Fig. 5. (a),(c)Zoomed image of foreground and background (b),(d) Wiener filtered image 
획득한 실험 영상에 대하여 초점이 맞지 않는 부분의 $\mathrm{PSF}$ 로 단순히 위너 필터링 할 경우, 그림 5 의 (b) 영상과 같이 블러 되었던 전경의 표지판과 같은 영역은 복구가 되 지만 배경의 나무와 같이 초점이 맞았던 영역의 에지 주변 에 인위적인 artifact가 생김을 알 수 있다. 이와 마찬가지로 그림 5의 (d) 영상에서도 배경의 달력 글자는 복구가 되지 만 전경의 글자가 왜곡됨을 확인할 수 있다. 따라서 초점 정량화를 통해 획득한 영상과 위너 필터링 한 영상을 정합 해야 하며, 기존의 지역적 SML과 지역적 분산을 이용한 방 법과 제안하는 방법으로 decision map을 구하여 정합한 영 상을 확대한 영상은 그림 6,7 과 같다.

그림 6의 실험결과 영상을 보면 지역적 $\mathrm{SML}$ 을 이용한 방법은 블러 되었던 전경 영역의 표지판의 복구 정도는 높 으나 decision map의 오차로 인해 초점이 맞았던 배경 영역 에 인위적인 artifact가 가장 많음을 알 수 있으며, 지역적 분산을 이용한 방법은 초점이 맞았던 영역의 인위적인 artifact는 줄였지만 전경 영역의 복구 정도가 낮음을 실험결과 를 확대한 영상을 통해 확인할 수 있다. 이에 비해 제안하는
방법은 전경 영역의 복구를 높이면서도 초점이 맞았던 배 경 영역의 artifact를 최소화함을 실험 결과를 통해 확인할 수 있다.

그림 6의 결과 영상과 같이 그림 7의 결과영상에서도 지역적 $\mathrm{SML}$ 을 이용한 방법은 블러 되었던 배경 영역의 복구 정도는 높으나 전경의 글자에 ringing artifact가 발생 했으며 지역적 분산을 이용한 방법은 초점이 맞았던 영역 의 인위적인 artifact는 최소화 하지만 블러 되었던 영역의 복구 정도가 낮음을 실험결과를 확대한 영상을 통해 확인 할 수 있다.

이에 비해 제안하는 방법은 블러 되었던 영역의 복구를 높이면서도 초점이 맞았던 영역의 artifact를 최소화함을 육 안으로 확인할 수 있다. 또한 결과 영상에 대하여 성능을 정량화 하면 표 1 과 같다. 성능을 정량화 할 때, 획득한 영 상과 $\mathrm{EdoF}$ 알고리즘을 수행한 결과 영상의 배경과 전경 영 역을 자동적으로 분할 할 수 없기 때문에 배경과 전경을 각각 수동적으로 분할하였으며 decision map의 오차로 인 해 원래 초점이 맞았던 부분에 발생한 artifact 정도는 획득

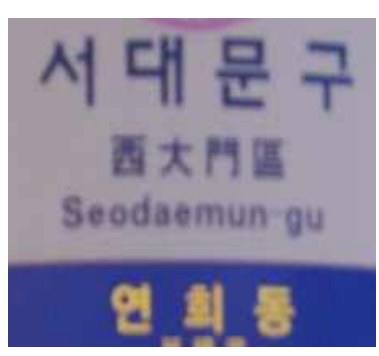

(a)

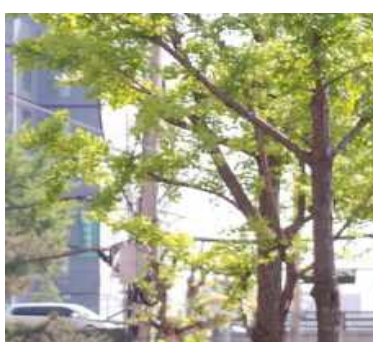

(e)

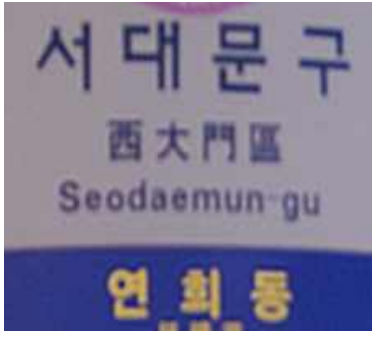

(b)

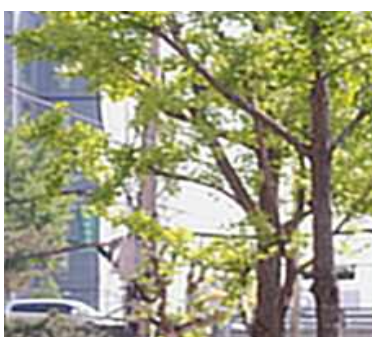

(f)

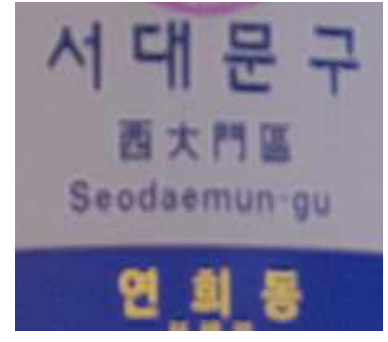

(c)

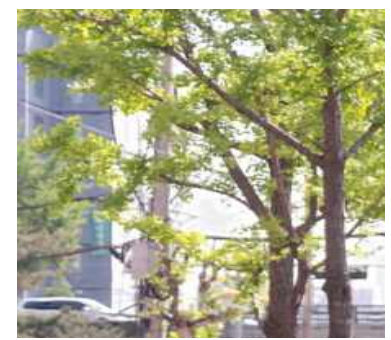

(g)

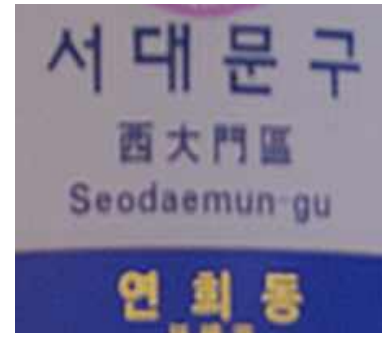

(d)

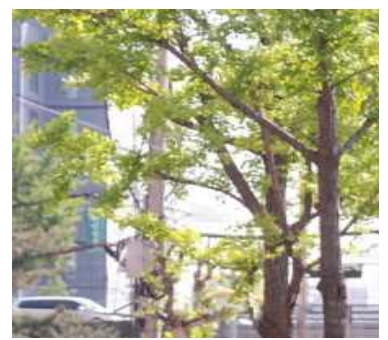

(h)

그림 6. 실험결과를 확대한 영상, (a)(e) 획득한 영상, (b)(f) 지역적 SML을 이용한 방법, (c)(g) 지역적 분산을 이용한 방법, (d)(h) 제안하는 방법 Fig. 6. Zoomed image of experimental result, (a)(e) Observed image, (b)(f) Local SML method, (c)(g) Local variance method, (d)(h) Proposed method 
한 영상에서 초점이 맞았던 영역과 이 영역에 해당하는 복 구된 영상의 영역과의 MSE (Mean Square Error)로 비교하 였다. 또한 복구 정도는 획득한 영상에서의 블러된 영역과 이 영역에 해당하는 복구된 영상의 영역과의 GMS (Gradient Magnitude Sum) 증가량을 이용하여 에지 성분의 증가 정도를 비교하였다 ${ }^{[18]}$.

\section{표 1. 제안하는 방법과 기존 방법의 성능 비교}

Table 1. Performance comparison of proposed method and conventional methods

\begin{tabular}{|c|c|c|c|c|}
\hline & \multicolumn{2}{|c|}{ 그림 6 } & \multicolumn{2}{c|}{ 그림 7 } \\
\hline & GMS 증가량 & MSE & GMS 증가량 & MSE \\
\hline SML & 0.66 & 0.2284 & 2.39 & 0.0046 \\
\hline Local variance & 0.18 & 0.0004 & 0.28 & $2.5351 \mathrm{e}-005$ \\
\hline Proposed & 0.50 & 0.0002 & 1.04 & $9.8884 \mathrm{e}-006$ \\
\hline
\end{tabular}

표 1에서 볼 수 있듯이, 제안하는 방법은 블러 되었던 영 역에서 GMS 수치가 SML 보다 낮지만 원래부터 초점이
맞았던 영역에서의 MSE의 수치가 기존 방법들에 비해 가 장 작으면서도 블러 되었던 영역의 복구를 통해 에지를 증 가 시켰음을 알 수 있다.

한편, 제안하는 방법의 잡음에 대한 강인성을 확인하기 위하여 $\mathrm{SNR}$ 이 $35 \mathrm{~dB}$ 인 잡음이 추가되었을 때에도 실험해 보았으며 결과 영상은 그림 8 과 같다. 잡음이 들어간 영상 에 대한 결과도 블러된 전경에 대한 복구정도와 원래 초점 이 맞았던 배경에 대한 artifact 최소화 정도가 기존의 방법 에 비해 제안하는 알고리즘이 우수함 실험 결과를 통해 확 인할 수 있다. 또한 블러 되었던 영역은 초점 정량화로 구한 decision map에 의해 위너 필터링 된 영상을 취하므로 잡음 이 제거된 영상을 얻을 수 있게 된다. 제안하는 방법에 의해 블러된 영역을 복구한 결과 영상은 원본 영상 보다 초점이 맞지 않은 부분의 에지는 증가시켰지만 잡음의 영향을 줄 여 잡음의 고주파수 양을 줄였기 때문에 원본 영상과 복구 영상간의 GMS 증가량으로 제안하는 알고리즘의 성능을 평가하지 못한다. 따라서 잡음이 추가된 영상의 경우는 $\mathrm{MSE}$ 와 GMS 증가량으로 성능을 비교하지 않고 주관적인

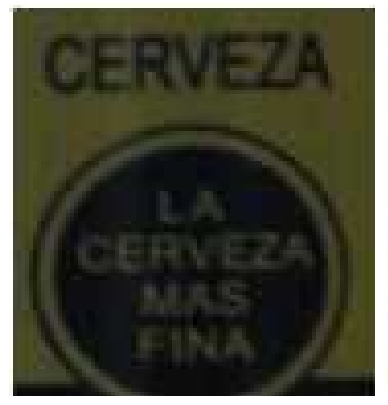

(e)

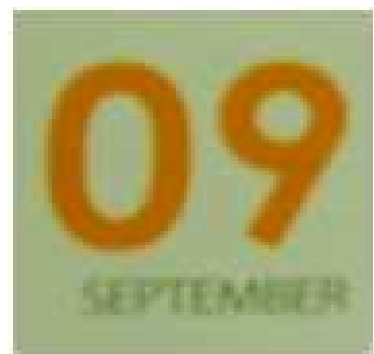

(e)

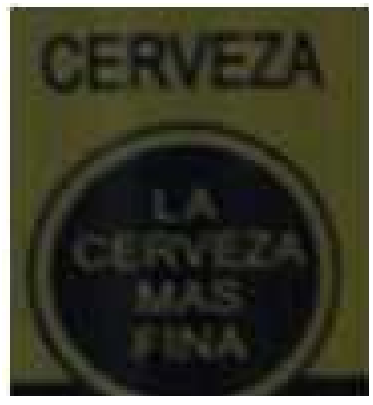

(f)

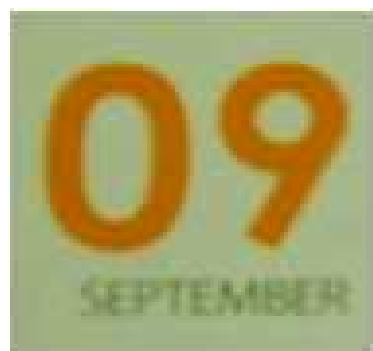

(f)

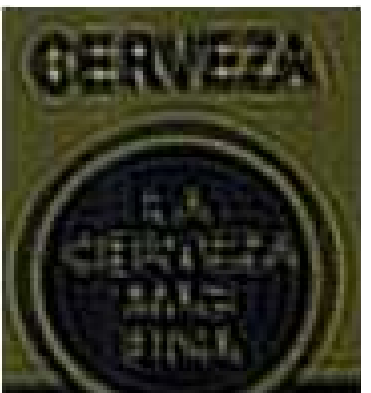

(g)

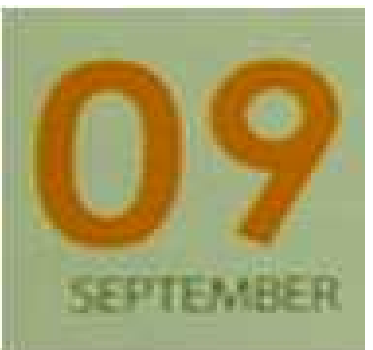

(g)

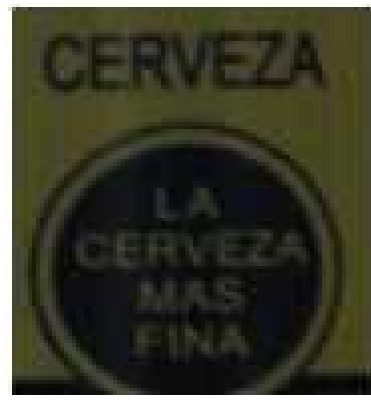

(h)

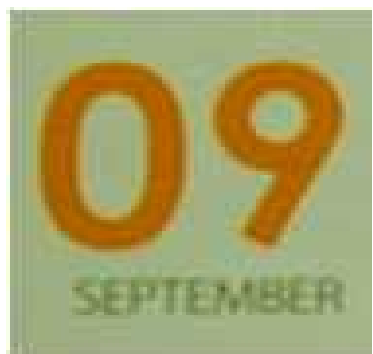

(h)

그림 7. 실험결과를 확대한 영상, (a)(e) 획득한 영상, (b)(f) 지역적 SML을 이용한 방법, (c)(g) 지역적 분산을 이용한 방법, (d)(h) 제안하는 방법 Fig. 7. Zoomed image of experimental result, (a)(e) Observed image, (b)(f) Local SML method, (c)(g) Local variance method, (d)(h) Proposed met 


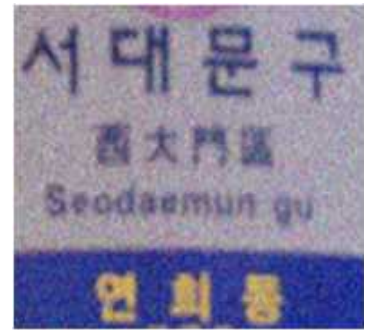

(e)

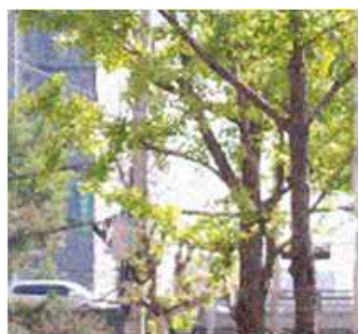

(e)

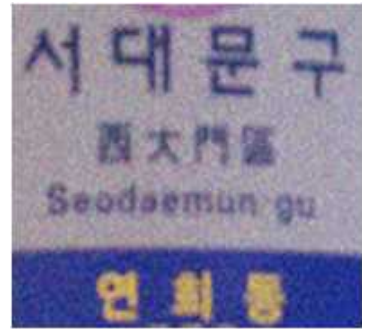

(f)

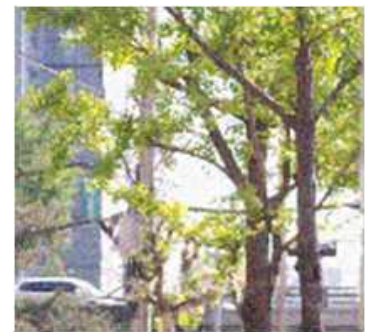

(f)

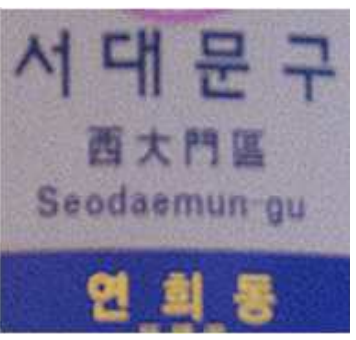

(g)

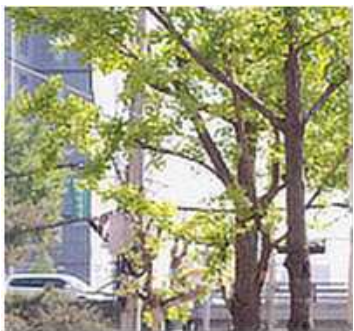

(g)

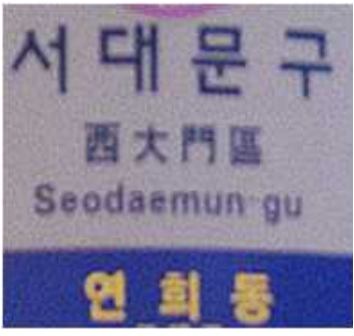

(h)

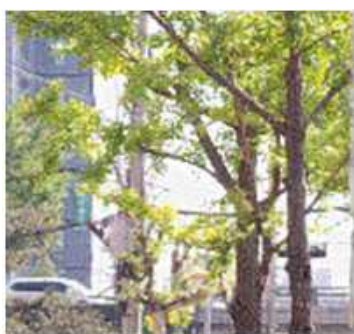

(h)

그림 8. 실험결과를 확대한 영상, (a)(e) $35 \mathrm{~dB}$ SNR을 가지는 획득한 영상, (b)(f) 지역적 SML을 이용한 방법, (c)(g) 지역적 분산을 이용한 방법, (d),(h) 제안하는 방법

Fig. 8. Zoomed image of experimental result, (a)(e) Observed image with 35dB SNR, (b)(f) Local SML method, (c)(g) Local variance method, (d)(h) Proposed method

화질평가만 수행하였다.

\section{V. 결 론}

피사계심도가 낮은 카메라로 영상을 획득 했을 때, 한 영 상 내에 초점이 맞은 부분과 맞지 않는 부분이 존재하게 되고 이를 복원하기 위해서는 초점 정량화가 필요하다. 기 존의 초점 정량화 방법은 획득한 영상의 고주파수 성분이 나 분산 값으로 초점이 맞는 영역과 맞지 않는 영역으로 나누었다. 따라서 초점이 맞지 않는 영역의 피사체가 고주 파수 성분을 가지고 있거나 잡음이 추가되었을 경우에는 초점이 맞은 부분과 그렇지 않은 부분을 잘 추정하지 못하 여 초점이 맞지 않은 부분의 복원이 잘 되지 않거나 원래 초점이 맞았던 부분에 artifact가 발생하는 문제점을 가진 다. 본 논문에서는 획득한 영상과 그 영상을 위너 필터링 한 영상과의 관계를 이용하여 대역통과 필터의 특성을 가 지는 초점 정량화 방법을 제안했으며 이를 이용하여 획득
된 영상과 위너 필터링된 영상의 정합을 통해 피사계심도 가 확장된 영상을 얻었다. 본 논문에서는 위너필터의 PSF 와 NSR 을 실험적으로 결정하여 사용하였으나 추후 여러 개의 파라미터를 가지는 위너 필터를 통과 시켜 초점이 맞 는 부분만 정합하는 semi-blind 복원 방법으로 확장할 수 있을 것으로 예상된다. 제안하는 초점 정량화 방법은 시뮬 레이션과 실험에서 기존의 방법보다 우수한 성능을 보여 피사계심도 확장에 유용하게 사용될 수 있을 것으로 예측 된다.

\section{참 고 문 헌}

[1] M. Bertalmio, P. Fort and D. Sanchez-Crespo, " Real-time, Accurate Depth of Field using Anisotropic Diffusion and Programmable Graphics Card," 2nd International Symposium on 3D data Processing Visualization and Transmission, pp. 767-773, Sept, 2004

[2] E. Dowski and W. Cathey, "Extended depth of field through wave-front coding," Optics, vol.4, no.11, pp.1859-1866, 1995.

[3] G. Muyo and A. Harvey, "Wavefront coding for athermalization of infrared imaging systems," SPIE, vol.5612, pp.227-235, 2004.

[4] E. Dowski and G. Johnson, "Wavefront Coding: A modern method of 
achieving high performance and/or low cost imaging systems," SPIE Annual Meeting, Denver, vol.29, pp.137-145, 1999.

[5] C. L. Tisse, H. P. Nguyen, R. Tessieres, M. Pyanet and F. Guichard, "Extended depth-of-field (edof) using sharpness transport across colour channels," SPIE Conference vol.7061, Sept, 2008.

[6] B. Forster, D. Van De Ville, J. Berent, D. Sage and M. Unser, "Complex Wavelets for Extended Depth-of-Field: A New Method for the Fusion of Multichannel Microscopy Images," Microscopy Research and Technique, vol.65, pp.33-42, 2004.

[7] R. J. Pieper and A. Korpel, "Image processing for extended depth of field," Optics, vol.22, no.10, pp.1449-1453, 1983.

[8] N. T. Goldsmith, "Deep focus: a digital image processing technique to produce improved focal depth in light microscopy," Image Anal Stereol, vol.19, pp.163-167, 2000

[9] P. J. Burt and R. J. Kolczynski, "Enhanced image capture through fusion." 4th International Conference on IEEE Computer Vision, pp.173-182, 1993.

[10] S. Li and B. Yang, "Multifocus image fusion using region segmentation and spatial frequency," Image and Vision Computing, vol.26, no.7, pp.971-979, 2008

[11] S. Kuthirummal and K. Nayar, "Shape from focus," IEEE Transactions on Pattern Analysis and Machine Intelligence, vol.16, pp.824-831, 1994.
[12] K. S. Choi, J. S Lee and S. J Ko, "New Autofocusing Technique Using the Frequency Selective Weighted Median Filter for Video Cameras," IEEE Transactions on Consumer Electronics, vol.45, no.3, pp.820-827, Aug, 1999.

[13] V. Maik, D. Cho, J. Shin and J. Paik, "Regularized Restoration Using Image Fusion for Digital Auto-Focusing," IEEE Transactions Circuits System and Video Technology, vol.17, no.10, pp.1360-1369, Oct, 2007.

[14] S. Kim, S. Jum, E. Lee, J. Shin and J. Paik, "Real-time Bayer-Domain Image Restoration for an Extended Depth of Field (EDoF) Camera, IEEE Transactions on Consumer Electronics, vol.55, no.4, Nov, 2009.

[15] M. Kristan, J. Pers, M. Perse and Sk. Kovacic, "A Bayes-spectral-entropy-based measure of camera focus using a discrete cosine transform," Pattern Recognition Letters, vol.27, no.13, pp1431-1439, Oct, 2006.

[16] P. Cao, M. Xing, G. Sun, Y. Li, and Z. Bao; , "Minimum Entropy via Subspace for ISAR Autofocus," IEEE Geoscience and Remote Sensing Letters, vol.7, no.1, pp.205-209, Jan. 2010.

[17] J Huang, C. Huang, S. Phoong, and H. Chen, "Robust Measure of Image Focus in the Wavelet Domain," International Symposium on intelligent Signal Processing and Communication Systems, 2005.

[18] R. C. Gonzalez, R. E. Woods, S. L. Eddins, Digital Image Processing Using MATLAB, Prentice-Hall, 2003.

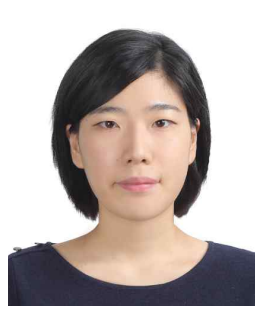

\section{차 수 람}

- 2006년 2월 : 이화여자대학교 전자정보통신학과 학사

- 2010년 3월 현재 : 이화여자대학교 전자공학과 석사 과정

- 주관심분야 : 카메라 영상처리, 영상화질개선

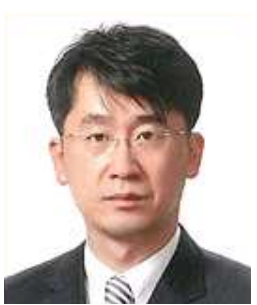

\section{김 정 태}

- 1989년 : 서울대학교 공과대학 제어계측공학과 학사

- 1991년 : 서울대학교 대학원 제어계측공학과 공학 석사

- 1991년 2004년 : 삼성전자 책임 연구원

- 1998년 2004년: Ph.D, Electrical Engineering and Computer Science, The University of Michigan, Ann Arbor

- 2004년 현재 : 이화여자대학교 전자공학과 부교수

- 주관심분야 : 통계적 신호처리, 영상신호처리, 의료영상 